\title{
Multimodal Acting and Performing
}

\author{
Andy Lavender
}

\section{Contents}

3.1 Modes, Modalities and the Actor as a Medium.......................................... 113

3.2 On Analysing Acts of Performance (in a Multimodal Situation)............ 118

3.3 Modes and Modalities of Performance......................................................... 124

3.4 Towards a Multimodal Performance Analysis........................................... 137

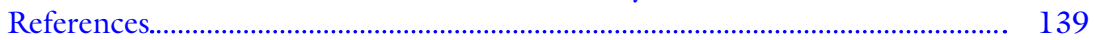

\subsection{Modes, Modalities and the Actor as a Medium}

This chapter considers how the work of the actor or performer might be understood with reference to ideas of multimodality. I should explain straight away that I sometimes use the terms 'actor' and 'performer' interchangeably, below, since I am less concerned here with distinctions that might be drawn between actors who play characters and performers who present something other than a fictionalised figure. 'Actor' and 'performer' for present purposes are individuals who convey an act of performance that we are interested to describe in a systematic way. I should also

\footnotetext{
A. Lavender $(\bowtie)$

Guildhall School of Music \& Drama, London, UK

e-mail: andy.lavender@gsmd.ac.uk

(C) The Author(s) 2021

L. Elleström (ed.), Beyond Media Borders, Volume 1, https://doi.org/10.1007/978-3-030-49679-1_3
} 
say immediately that such description is an attempt to transpose Lars Elleström's ideas about media modes and modalities (2020) to a consideration of performing. Of course, the actor is not a 'medium' in the way of the media in which she performs (theatre, film, radio drama, etc.). And yet the actor has a communicative function that can be elucidated according to the principles by which media communicate. There are some conceptual similarities between this project and that of Miriam Vieira in the present publication, which demonstrates how architecture as a medium intersects with considerations of embodiment and perspective (2020). I examine below how we can see the actor as what Elleström describes as a 'technical medium of display' (2020: 33-40) and how this is always a matter that involves the perception of the spectator.

Elleström makes his case in an essay entitled "The modalities of media: A model for understanding intermedial relations" (Elleström 2010) and revises and expands upon it in the current publication (2020). As Jørgen Bruhn explains in a draft to his article in the present publication, Elleström's approach was novel in taking "seriously the fact that many of the insights of both media theory and interart studies had very clear parallels in the field of multimodal studies" and in elaborating a scheme that combined intermedial and multimodal perspectives within a single system of communications analysis (Bruhn 2020; see also Lotherington 2020: 218, 226). In multimodal approaches, communicative modes are notably diverse and include, for instance, written texts, visual images, diagrams, typography, facial gestures, and nods of the head (see, e.g., Bateman et al. 2017: 16; Djonov and Zhao 2014: 1; Fernandes 2016: 1). A key principle is the transactional nature of modes, their work as communicative elements within a process of signification. As Gunther Kress suggests, "Mode is a socially shaped and culturally given resource for making meaning" (2014: 60, original emphasis; see also Jewitt 2014: 22). This aligns with scholarly interests elsewhere in media and mediation, and Elleström's work brings a semiotic orientation (concerned with meaning making) to considerations of the technical and aesthetic infrastructures of media, which are themselves pressured by specific historical and industrial situations. As Heather Lotherington observes, "[m]edia and mediation are exceedingly complex in today's communication landscape. A media product or medium exists in historical-social-cultural space as well as physicalsensorial-cognitive space." As she suggests, "Elleström's [...] intermediality 
paradigm offers analytical specificity and categorization that is helpful in understanding contemporary communication" (2020: 222, 229).

In some quarters, 'mode' (as a way of doing something, or the particular form that a phenomenon, condition or activity takes) precedes 'modality', which describes ways in which the activity/phenomenon/object can be seen to express its mode. However, we are with Elleström, for whom modalities (of which there are four) should be ascribed conceptually before modes. The modalities and modes then operate synchronously within a larger interrelated system of communication. Indeed, the communicative aspect (shaped by Kress's 'culturally given') is key. This functional approach emphasises the role of the receiver/perceiver amid mediation and circumscribes the formation and efficacy of media in the first place. As Elleström summarises:

there are four media modalities, four types of basic media modes. For something to acquire the function of a media product, it must be material in some way, understood as a physical matter or phenomenon. Such a physical existence must be present in space and/or time for it to exist; it needs to have some sort of spatiotemporal extension. It must also be perceptible to at least one of our senses, which is to say that a media product has to be sensorial. Finally, it must create meaning through signs; it must be semiotic. This adds up to the material, spatiotemporal, sensorial and semiotic modalities. $[\ldots]$ no media products or media types can exist unless they have at least one mode of each modality $[\ldots]$ the four media modalities form an indispensable skeleton upon which all media products are built. (Elleström 2020: 46)

The skeleton is formed of two distinct kinds of bone (if you will allow the analogy to be continued). Three of the modalities - the material, spatiotemporal and sensorial-are 'presemiotic' (2020: 47), in that they do not originate from cognition but rather describe structuring aspects that will then affect cognition. The fourth modality, the semiotic, Elleström describes as "the frame for understanding representation. All media products are semiotic because if the sensory configurations with material, spatiotemporal and sensorial properties do not represent anything, they have no communicative function" (2020: 49). The four modalities, then, are always mutually in play in some way in any process of mediation, and each of the modalities can be described by way of a subset of modes. As Elleström suggests: "All media are multimodal in that they must have at least one mode from each modality" (2020: 53). 
The modalities and modes are given in tabular form in the 2010 version of Elleström's essay, under the headings 'Modality', 'What the modality is', and 'The most important modes of the modality'. For example, the 'sensorial modality' is described as "The physical and mental acts of perceiving the interface of the medium through the sense faculties" and its most important modes given as "seeing, hearing, feeling, tasting, smelling" (2010: 36). This schematic organisation allows for a critical perspective and a procedure-one based on recognising specific features and distinctions and accounting for media operations as, continuously, a combination of modalities and modes (see Elleström 2010: 24).

The model is geared towards elucidation and concerns communication that is itself, Elleström observes, always about conveying "cognitive import" (2020: 12-13; the revised version of the essay provides greater emphasis on this aspect). The four modalities combine within media processes that are at the heart of signification, understood here in terms of 'representation' in its semiotic sense-that is, as a means to transact perception on the part of the perceiver, in a domain of cognition. The fulcrum is the communicative act. A medium in this sphere of analysis is only effectual insofar as its operation permits what Elleström calls a "media product", defined as "the intermediate stage that enables the transfer of cognitive import from a producer's to a perceiver's mind" (2020: 13). This is to an extent metaphorical for, as Elleström goes on to say, the model envisions not solely a single line of transfer from one individual to another but the possibility of multiple producing elements that converge into media products conveyed to multiple perceivers. In any case:

A media product is a single physical entity or phenomenon that enables inter-human communication [...] [it] may be realised by either non-bodily or bodily matter (including matter emanating directly from a body), or a combination of the two. [...] other bodies, such as the bodies of actors, may be used as media products. $(2020: 8,13,14)$

Let us remain with the bodies of actors. As Elleström suggests, a media product "requires some sort of perceptible physical phenomenon to come into existence" (2020: 33) —and such phenomena he calls (in a slightly self-deprecating way, noting the "cumbersome" nature of the term) "technical media of display of sensory configurations" (2020: 34). The actor is one such, for she fulfils a central criterion of the technical medium of display-she "mediates sensory configurations in the context of 
communication; [she] realises and displays the entities that we construe as media products" (2020: 34).

In what way can the actor be described as a medium of communication? We might start by considering the actor as character, probably the dominant paradigm of Western representational performance, whether in theatre, film, television or radio drama, or other kinds of performance such as appearance in adverts or short-form online videos. The communicating aspects are manifold, which means that the actor can be thought of as a technical medium comprised of multiple internal technical media of communication: the actor's voice, convening signifying information both through sonic inflections and verbal utterance; the actor's gesture, communicating through learned socio-cultural codes and aesthetic codes; the actor's costume, but also the manner in which costume items are worn (a jaunty angle to a hat, an overweening deportment of a uniform, an embarrassed donning of a tie by a teenager); the rhythm of movement; the signifying aspect of entrances, exits and other positional manoeuvres; the nature of interaction with other actors and scenic objects; and any significant liaison-by eye contact, gesture or direct address - with the spectator. Elleström, following Peircean semiotics, describes such elements variously as iconic, indexical and semiotic (2020). These prospective signifying aspects can variously be conceived as media products if and where they effect perception on the part of the spectator. The actor operates within the structures and processes of the medium in which she performs-this could be film, theatre, television and so forth (for there are others)which will itself be comprised of media products that depend upon the organisation provided by, for example, script, direction, lighting, sound design and other features that help construct the medium. The actor is thereby herself a complex technical medium, disporting media products by way of (for instance) gesture, utterance and movement, within a larger media product that may form what Elleström calls "one perceptual gestalt" (2020: 76). There may be differences to be drawn between the appearance of an actor in a live situation to a co-present audience; an actor in a live situation appearing to a remote audience; and an actor in a situation that was recorded previously, whether through analogue or digital technologies, accessed at a different time by one or more audience members. In terms of Elleström's model, we are in the realms of distinct qualified media types that operate through slightly different arrangements of technical media of display. For present purposes, however, I suggest that we consider 'actor/performer' as a technical medium comprised of multiple 
internal technical media of communication and move from this to a modal description of the actor's work and function.

How do we make sense of the actor's performance as an isolable feature of mediation within this larger mediation machine? Elleström addresses Yeats's question: "How can we know the dancer from the dance?"

On one hand, the dancer and the dance are inseparable in the sense that they are the same material entity occupying physical space and time. On the other hand, they are two different things. Whereas the dancer is a body acting as a technical medium of display, the dance is a function of the material bodya media product. (2020: 36)

This also puts me in mind of ripples from the throw of a stone into a pond or the reflections of one mirror in another-a set of interconnected iterations that layer perception as an act, not only as a single instance but as a composite in which we can find signification in the part as well as the whole. This gives us a clue as to how performance might be 'read'-we can find its agency and affect in something as simple as a change of eyeline or the travel of a finger on the part of an actor; as multiple as the interactions of a group of actors within a sustained scene of physical interchange; and as multi-layered as the transactions achieved when (for example) a film captures a relation between actors within a mise en scène that draws attention to its signifying devices while narration 'lands' for the spectator in a moment of clarity, exuberance or awful realisation. This is perhaps to say that the actor's performance in itself will in some manner always allow only a partial reading; for it cannot be self-contained but will necessarily require contextual coordination with the film, staging or other set of circumstances in which the performance is presented. No performance is innocent of the medium in which it appears. That said, we must start somewhere, and for the purposes of this chapter, the actor's body is as good a place as any.

\subsection{On Analysing Acts of Performance (in a Multimodal Situation)}

My proposition here is that we can transpose Elleström's idea of modalities and modes from a consideration of specific media to a consideration of specific acts of performance. I will come back to how we might do this, but first I should address the obvious question: Why would we want to do it in the first place? 
One answer is that it would be helpful to have a system to analyse performance that can accommodate the range of performances that now inhabit the contemporary cultural scene. This includes character-based acting (whether in film, television, online performances, radio or theatre); acting that slides between presenting a character and presenting the self; the appearance of performers in a wider array of events, situations and installations; the performance of singers and other artists in diverse kinds of real-time and recorded presentation; the appearance of individuals, who may or may not be 'celebrities', in reality-based entertainments and scenarios; the actions or interactions of members of the public (for want of a better phrase-we might also say 'spectators' or 'participants'), who become active in events in more or less significant ways; and the appearance of politicians and other figures in the public sphere that can be assessed through the critical instruments of performance studies.

You might reasonably suggest that this is too disparate a list, gathering dissimilar kinds of performance, and I wouldn't necessarily disagreeexcept that a second answer to the question ('why consider modes of performance?') is that performance takes place in this highly interconnected and pluralised environment, where we are often witness to (and sometimes party to) different kinds of performance every day and where a cultural slippage across media and types of performance is now routine rather than irregular. It is no accident that Elleström developed his model expressly for an intermedial situation, with distinct media operating in interdependence (Elleström 2010: 12). The field of acting and performance lies in a contemporary performance scene that is heavily mediated and profoundly plural-not just in the sorts of performance that we see but in its varying registers and slippage across forms. Indeed, there has been a growing consensus in both communications studies and performance studies concerning the mixed and plural nature of the cultural and communicative sphere. In Multimodality, for instance, Bateman et al. describe an increasingly interdisciplinary communicative environment, in which "we no longer have separate media; we have instead media that are capable of doing the jobs of many" (2017: 14). The instances given of this include an iPad showing newspaper pages or a website playing music - and while these may be more prevalent in some parts of the world than others, the acceleration of cross-medial communication is indisputable. Performance theorist Shannon Jackson makes a related point from a different disciplinary location, in her discussion of "the hypercontextuality of performance", which she sees as both a condition (performance operates 
across genealogical fields) but also a challenge (performance is subject to dispersal and has an "intensely contingent status") (Jackson 2004: 6). The figure of the actor/performer takes on a more protean form in this environment (see, for instance, Dunbar and Harrop 2018: 13). In which case, it becomes useful to consider whether there is a common way of calibrating performance amid such varied and disparate instances.

There are many extant systems for analysing performance. One way of taking a perspective on this new project of 'modal' analysis is to consider the viability of established systems for current performance situations. This is not to argue that all the old models must be done away with-far from it. Rather, it is a check upon the aesthetic- and context-specific aspects of acting/performing systems, which tend to be more adequate for some kinds of work than for others. Every system of performance and performance analysis is located culturally and has its own specific history. To turn first, briefly, to the most celebrated of all (at least, in a modern Western context), Konstantin Stanislavski's system of actor training, developed over the first part of the twentieth century and consolidated broadly between the 1940s and the 1970s. Stanislavski's ideas had a troubled journey of transmission into print, subject to delays and editorial partialities. His influential volume An Actor Prepares (first published in Russian in 1936), for example, was described by Jean Benedetti as "a pale shadow" of the larger intended oeuvre, An Actor's Work (Benedetti 1999 [1988]: 366). The approach and practices that Stanislavski recommended likewise enjoyed a mixed journey into different spheres of influence. In An Acrobat of the Heart, Stephen Wangh provides a summary of a widely argued historical trajectory, tracing selective strands of Stanislavski's 'system' through their migration to other territories. Stanislavski, Wangh suggests,

searched for a method that would depend on inner, psychological practices. $[\ldots][\mathrm{He}]$ developed the sense-memory and 'affective memory' exercises. It was these 'internal' techniques that Stanislavski's students Richard Boleslavsky and Maria Ouspenskaya brought from Russia to New York in 1923. And it was this work that they taught at their American Laboratory Theater where Harold Clurman, Stella Adler, and Lee Strasberg came to study. (Wangh 2000: xxxiii)

As students of theatre know, this set of practices provided the structure and impetus for what would become the American Method system, geared around the inner exploration on the part of the actor of the individual and 
psychological dynamics of the character, drawing extensively on personal experience and individual intuition. Meanwhile, as Wangh describes, "Stanislavski $[\ldots]$ realized that by concentrating so completely on the actor's mind, he had ignored the actor's body. In his later years Stanislavski developed a system of what he called 'physical actions"' (xxxiv). The diffusion of influence is complicated by way of the inflections made by acolytes, including Michael Chekhov's work during the 1930s. Chekhov (nephew of playwright Anton Chekhov) had been a member of Stanislavski's First Studio and had worked on Stanislavski's more physically oriented approach. He disseminated his own adaptation and interpretation of this, focusing on the 'psychological gesture', in his work in Germany, Lithuania, England and the US. 'Media products' associated with Stanislavski's approach, then, are not uniform.

Stanislavski's teaching had a fraught history in its own right, both in terms of its codification through published writings - which took time and required extensive editing that Stanislavski himself was only partly involved in - and the differing set of understandings that ensued, as the work gained traction in different countries and through the work of different disciples. I do not mean to unpick that legacy and its differences here (for useful discussion, see Carnicke 2009 and Pitches 2006). The larger point is that however you nuance it-whether as predominantly concerned with internal psychology, the actor's interior state, or external gesture and the physical work of the performer-Stanislavski's system applies expressly to the presentation of character that typically derives from work in relation to a playtext. And that simply doesn't apply to the context, artistic type, mode of production, or technical requirement of many instances of performance today. Stanislavski's system remains useful for the development of performance in narrative-based drama in which characters interact within a broadly realist aesthetic. It is inadequate as a means by which to prepare or explain performance in, for instance, Heiner Müller's Hamletmachine (1977, first presented at the Théâtre Gérard Philipe, Paris, France, in 1979) or Punchdrunk's Sleep No More, the company's site-specific version of Macbeth (presented at the McKittrick Hotel in New York from March 2011, and still running as I write)-let alone a repertoire of performances in the wider field, including gallery-based events, virtual reality projects and postdramatic dance-based pieces. Stanislavski's methods, with their apparatus of 'magic ifs', intentions, circles of attention, and units and objectives, are applicable in some of these instances, but not to all and certainly not uniformly. 
The same is true of other systems for producing and analysing performance. Let us consider Michael Kirby's celebrated spectrum (1972) describing different modes from acting to performance-an important contribution to understanding performance in a gathering postmodern context and an account whose attempt to cover a range of performance manifestations evinces a not-dissimilar ambition to the present essay. Kirby remarks that his work was inspired in particular by the Happenings of the early- to mid-1960s, where

every aspect of theatre in this country has changed: scripts have lost their importance and performances are created collectively, the physical relationship of audience and performance has been altered in many different ways and has been made an inherent part of the piece, audience participation has been investigated, 'found' spaces rather than theatres have been used for performance and several different places employed sequentially for the same performance, there has been an increased emphasis on movement and on visual imagery. (Kirby 1972: 12)

In response to this situation-which has become a norm in many different locations-Kirby proposed a performance spectrum from 'nonacting' to 'acting', with (for example) 'Non-matrixed Performing' at one end of the spectrum and 'Complex Acting' at the other (Kirby 1972: 8). The value of Kirby's spectrum lies in its attempt both to incorporate and distinguish between a wide range of performance activity and its insistence that the project is one of classification rather than evaluation (value judgements as to whether the acting is 'good' or not, Kirby insists, are irrelevant). Its difficulty, however, is that it doesn't elaborate a set of technical calibrations of any degree of subtlety for use by either the critic or the performer-rather, it describes the place of a performance on a spectrum that is largely determined by the extent to which the individual performer can be seen to be engaging in representation-based characterisation, which thereby provides a norm against which things are judged. Kirby suggests that the "simplest characteristics that define acting [...] may be either physical or emotional. If the performer does something to simulate, represent, impersonate and so forth, he is acting" (1972: 6). 'Acting' is the standard against which other kinds of performance-non-acting-are adjudicated.

The spectrum is yet more problematic in relation to contemporary performances where we may well observe 'acting' and 'non-matrixed 
representation' in the same performance-as has been the case for over a generation, at least. Twenty-five years after Kirby's "On acting and notacting", Philip Auslander's influential collection of essays entitled From Acting to Performance was published (1997). Auslander was attempting to assess performance in and amid the ascendant paradigm of postmodernism. The New York-based company The Wooster Group provides a reference point. As Auslander says, "Wooster Group performances [...] are less representations of an exterior reality than of the relationship of the performers to the circumstances of performance. Their style of performing, which at once evokes and critiques conventional acting, could be described as performance 'about' acting" (1997: 41). Auslander's essays on this new performance scene are perceptive but, as with Kirby, provide a theoretical perspective rather than a set of calibrations for use by contemporary performers or that enable precise technical descriptions of contemporary performance. From the 1960s onwards, the incursion of modes of performance other than acting has been noted, analysed, and indeed taught. Can we conceive of a rubric for this extensive diversity of performance that might help us to place it, critique it and teach it by way of a single continuum of analysis?

One further brief detour, by way of a partial affirmative. In 1928, Rudolf Laban published Kinetographie Laban, which set out the basis for 'Labanotation', his system for describing and classifying human movement. Laban describes four categories: Body, Shape, Space and Effort (Dynamics). These key components can be organised by way of eight efforts (as outlined below) that each has four components: Space/Focus (Direct or Indirect), Time (Quick or Sustained), Weight (Heavy or Light) and Flow (Bound or Free). The system is represented in tabular form in Table 3.1.

Laban's system addresses human movement, so while it has proved to be consistently useful for actors and performers, it cannot provide a comprehensive means of classifying performance activity. You might also suggest that this modernist effort at exhaustive categorisation is in any case now inappropriate to the mixed and messy, hybrid and fluid scene of contemporary performance. The task before us is to outline a scheme that allows for close analysis of a wide range of instances and that recognises variety within a system designed to accommodate difference. Allow me to attempt just such an effort in a post-postmodern moment, based on a reworking of Elleström's modalities and modes. As we saw above, Elleström described the relation between modes and modalities in tabular 
Table 3.1 Rudolf Laban's eight efforts of movement and their four components (the system is tabulated in various forms; the one given here is from Espeland 2015)

\begin{tabular}{lllll}
\hline & Direction & Speed & Weight & Flow \\
\hline Punch & Direct & Quick & Heavy & Bound \\
Slash & Indirect & Quick & Heavy & Free \\
Dab & Direct & Quick & Light & Bound \\
Flick & Indirect & Quick & Light & Free \\
Press & Direct & Sustained & Heavy & Bound \\
Wring & Indirect & Sustained & Heavy & Bound \\
Glide & Direct & Sustained & Light & Free \\
Float & Indirect & Sustained & Light & Free \\
\hline
\end{tabular}

Source: Todd Espeland, The Drama Teacher, 2015; used by permission from Theatrefolk Inc

form, and I propose to retain this schematic approach in the section that follows - noting in passing that it provides a means of calibrating interrelations between components that is not entirely dissimilar to Laban's system outlining categories of movement and their respective modal expressions.

The challenge, then, is whether we can elaborate a scheme for analysing performance that is adequate to a range of contemporary performance acts. I am aware of the dangers, for any system that seeks to be widely inclusive may then appear to be context-free (so apolitical) and only vaguely specific (so inappropriate for a detailed analysis). I would prefer a cultural materialist approach that accommodates local specificity within a common scheme, one that seeks to provide a useful tool for analysis of apparently diverse objects of performance. The effort is not to reduce everything to a single paradigm but to move towards a system that is sufficiently flexible to recognise new forms and combinations whilst both allowing and accounting for their differences.

\subsection{Modes and Modalities of Performance}

Elleström describes four key modalities that provide the underpinning skeleton upon which any media product is conveyed. As we have seen, these can be represented schematically, along with the respective modes that attach to the modalities (see Elleström 2010: 36). I do not propose a direct reading of the work of the performer by way of Elleström's four modalities - although such a reading would be possible, allowing that the 
actor herself is a medium of communication. Rather, I suggest that we can identify four key modalities that apply to any human act of performance, taking performance here in its presentational/representational aspectwhat Jon McKenzie describes as 'cultural performance' rather than 'organizational performance' or 'technical performance' (McKenzie 2001). In other words, we are concerned with the scope of performance that in Kirby's spectrum moves from character-based acting through to nonmatrixed performance-but we are looking for a set of coordinates to help describe the composition and effect of each sort of performance before us.

The notion of modalities of performance provides us with such coordinates. We can assign four key modalities: the emotional, the physical, the discursive and the contextual (these are further defined in Table 3.2). Each can be addressed in relation to specific modes that apply to the modalitysome one or more of which will be present in the performance modality in question. All four modalities will be describable in any performance act, even if one or more are not predominant. The flexibility and plural potential combinations mean that the system of analysis can be applied to a wide range of performance instances. You might protest that this is like creating a map of the world that is as large as the world, if it allows for any and all possible performance-except that this is a portmanteau scheme. The four modalities are always structurally defining in some manner, their interconnection and combination variable, the specific arrangement of modes flexible.

In Elleström's table, the modalities of media are accompanied by respective modes that apply to the modalities. It is worth noting that Elleström has removed the table from the extended version of the article presented in the present publication (2020). In correspondence during the editing process, he suggested that this was "not at all because I think it's wrong as such to use such a table, but because it prompted some simplified and misleading uses of the concept of media modalities". Informed by Elleström's model—but mindful of his caution —we can outline something similar in relation to modalities and modes of performance, as seen in Table 3.2.

I should emphasise that the model is presented initially as a way of reading and categorising performance. It may subsequently inform ways of preparing for and producing performance-it would certainly be possible to conceive a range of exercises and rehearsal-room approaches that focus on a modal approach to the work in hand, in order to fine-tune presentation within a particular modality and interrelations between modes. This 
Table 3.2 Modalities of performance (Lavender, after Elleström 2010: 36)

\begin{tabular}{|c|c|c|c|}
\hline Modality & What the modality is & Modes include & Applications include \\
\hline Emotional & $\begin{array}{l}\text { The apparent emotional } \\
\text { state of the performer } \\
\text { and/or character/ } \\
\text { persona (bearing in } \\
\text { mind that the actual } \\
\text { emotional state of the } \\
\text { performer may be } \\
\text { different from that of } \\
\text { the character/persona } \\
\text { presented) }\end{array}$ & $\begin{array}{l}\text { Disengaged/ } \\
\text { unemotional } \\
\text { Focused/ } \\
\text { task-oriented } \\
\text { Bored } \\
\text { Disinterested } \\
\text { Distracted } \\
\text { Mildly engaged } \\
\text { Affectionate } \\
\text { Happy } \\
\text { Delighted } \\
\text { Concerned } \\
\text { Angry } \\
\text { Sad } \\
\text { Grieving }\end{array}$ & $\begin{array}{l}\text { Particularly relevant to } \\
\text { character-based acting. Can } \\
\text { be important to some } \\
\text { performance art } \\
\text { manifestations, especially } \\
\text { where the focus is on the } \\
\text { lived experience and } \\
\text { present state of the } \\
\text { performer }\end{array}$ \\
\hline Physical & $\begin{array}{l}\text { The physical disposition } \\
\text { of the performer, } \\
\text { comprised of bearing, } \\
\text { gesture, movement and } \\
\text { corporeal interaction } \\
\text { with space, objects and } \\
\text { other individuals }\end{array}$ & $\begin{array}{l}\text { Active } \\
\text { Reactive } \\
\text { Passive } \\
\text { Fast } \\
\text { Slow } \\
\text { Laboured } \\
\text { Elegant } \\
\text { Constrained } \\
\text { Uninhibited } \\
\text { Tense } \\
\text { Relaxed }\end{array}$ & $\begin{array}{l}\text { All forms of performance, } \\
\text { but especially to the fore in } \\
\text { dance, circus, promenade } \\
\text { pieces and other forms in } \\
\text { which physical registers } \\
\text { predominate }\end{array}$ \\
\hline Discursive & $\begin{array}{l}\text { The functional aspect } \\
\text { of the performer in } \\
\text { relation to the } \\
\text { conveyance of story, } \\
\text { theme, and/or } \\
\text { meaning (whether } \\
\text { through verbal } \\
\text { utterance, embodied } \\
\text { action or symbolic or } \\
\text { otherwise signifying } \\
\text { appearance) }\end{array}$ & $\begin{array}{l}\text { Informational } \\
\text { Explanatory } \\
\text { Revelatory } \\
\text { Knowing } \\
\text { Naïve } \\
\text { Contextual } \\
\text { (triangulated) } \\
\text { Authoritative } \\
\text { Innocent }\end{array}$ & $\begin{array}{l}\text { Of varied relevance, with } \\
\text { diverse registers from an } \\
\text { overt narrator function to } \\
\text { abstract non-matrixed } \\
\text { performance }\end{array}$ \\
\hline
\end{tabular}


Table 3.2 (continued)

\begin{tabular}{|c|c|c|c|}
\hline Modality & What the modality is & Modes include & Applications include \\
\hline Contextual & $\begin{array}{l}\text { The predominant } \\
\text { context in which the } \\
\text { performer appears, } \\
\text { particularly in relation } \\
\text { to ways in which the } \\
\text { performance will be } \\
\text { understood beyond its } \\
\text { immediate emotional, } \\
\text { physical and narrational } \\
\text { modalities; the } \\
\text { signifying and/or } \\
\text { affective social, cultural } \\
\text { or aesthetic structures } \\
\text { in which the } \\
\text { performance is } \\
\text { manifested }\end{array}$ & $\begin{array}{l}\text { Scenographic } \\
\text { Compositional } \\
\text { Presentational } \\
\text { Representational } \\
\text { Environmental } \\
\text { Relational } \\
\text { Interrelational } \\
\text { Affirmative } \\
\text { Distractive }\end{array}$ & $\begin{array}{l}\text { More notably to the fore in } \\
\text { some dance pieces, } \\
\text { installations and site- } \\
\text { specific events. Particularly } \\
\text { relevant in pieces that } \\
\text { feature audience/spectator } \\
\text { participation or action }\end{array}$ \\
\hline
\end{tabular}

is not my immediate priority in the present essay, where I am approaching performance as a critic after the act, rather than from the perspective of an actor or director of the act. That said, the two perspectives are by no means irreconcilable, and the work of developing a modal approach to performer training could be highly productive.

We can tabulate the relationship between modalities and modes as seen in Table 3.3. The modalities operate in relation to the perceiver. That is to say, for example, the emotional modality is relevant insofar as the emotional state presented by the performer is ascribed by the perceiver. It matters less what the actual emotional state of the performer is (although this may also be relevant). If a character played by an actor, for example, appears morose, the emotional condition of the actor herself is a secondorder concern. The first-order concerns are the suitability of the apparent emotional state to the material in hand and (for this is not quite the same thing) the effect (potentially both in cognition and affect) of the apparent emotional state on the perceiver.

The physical modality likewise may involve techniques of performance that separate the appearance of physical effort from the actual physical effort of the performer (for example, being breathless after running may 
Table 3.3 Relationship between performance modalities and modes

\begin{tabular}{ll}
\hline Modality & Modesinclude \\
\hline Emotional & $\begin{array}{l}\text { Disengaged/unemotional, Focused/task-oriented, Bored, Disinterested, } \\
\text { Distracted, Mildly engaged, Affectionate, Happy, Delighted, Concerned, } \\
\text { Angry, Sad, Grieving } \\
\text { Active, Reactive, Passive, Fast, Slow, Laboured, Elegant, Constrained, } \\
\text { Phinhibited, Tense, Relaxed }\end{array}$ \\
Discursive & $\begin{array}{l}\text { Informational, Explanatory, Revelatory, Knowing, Naïve, Contextual } \\
\text { (triangulated), Authoritative, Innocent }\end{array}$ \\
Contextual & $\begin{array}{l}\text { Scenographic, Compositional, Presentational, Representational, } \\
\text { Environmental, Relational, Interrelational, Affirmative, Distractive }\end{array}$ \\
\hline
\end{tabular}

belong to the character rather than the actor). A range of techniques are employed in drama schools across the world to help performers demonstrate subtlety and range within emotional and physical modalities. The point of the system presented here is to delineate how the modes of these modalities might be read in the performance act.

The discursive modality is to do with the meaning and significance that the spectator ascribes to the performance that is presented. This will depend upon additional information presented by (for example) other characters/performers in the piece, the arrangement of narrative, and scenic organisation such as, for instance, the configuration of lighting to create a threatening environment. The performer herself does not necessarily produce the communicative material that circulates here, but her performance is inextricably bound up with it and is enmeshed in a meaningrepertoire such that every instance of her performance is readable in and through the discursive modality. This applies even in more abstract pieces, where story is not at issue but nonetheless figurings of performance dynamics produce information for the spectator.

Something similar applies in relation to the contextual modality. For example, it matters to some members of the audience who go to see Benedict Cumberbatch playing Hamlet that Cumberbatch is a film star whose performances carry their trace in the memories of the spectator. It matters to some to see a 'first night', which comes with the added frisson of performers under the pressure of press night, or the sense of being among the first to witness a new piece. It matters to some to see a performance at a specific venue (one of my pilgrimages of a kind was to the Theater am Schiffbauerdamm in Berlin). It matters to some that the 
performer is one's daughter in a school play. If the discursive modality describes signifying details and meaning-ensembles that are generated by or presented within the performance itself, the contextual modality describes significant circumstances and situational details surrounding the performance that may have a bearing for perceivers.

In order to explore how the modalities and modes might be deployed, I will examine briefly four diverse instances: a performance by the actor Olivia Colman in the film The Favourite (character-based acting working from text); an excerpt from the opening scene of debbie tucker-green's play ear for eye (a theatre performance that is text-based but without the sense of character depth that is entailed by more narrative-based drama); the appearance of the pop star Miley Cyrus in the episode of the Netflix drama series Black Mirror entitled 'Rachel, Jack and Ashley Too'-Cyrus plays an intertextual version of herself as before-the-camera pop star in a narrative in which she is behind-the-scenes victim of her own celebrity; and the appearance of performers in Brett Bailey's installation Sanctuary. The selection deliberately moves across different sorts of characterisation, different dramatic genres and distinct modes of presentation. With all the analyses that follow, I will restrict myself to a fairly limited palette of modes, in order to suggest predominant features.

\subsubsection{The Favourite (2018)}

Written by Deborah Davis and Tony McNamara, produced by Fox Searchlight and directed by Yorgos Lanthimos, The Favourite is a movie set in 1708 and thereafter in the Court of Queen Anne, monarch of a newly unified Great Britain. It focuses on the triangular relationships between Anne and the cousins Sarah Churchill, Duchess of Marlborough, and Abigail Hill (later Baroness Masham), depicting a rivalry between the two women for Anne's favour. As such, the film is both a period drama and a character study, exploring in particular the interpersonal dynamics between the three women: Olivia Colman, who played Anne, won the Academy Award (Oscar), BAFTA Award and Golden Globe Award (among others) for best actress for her performance in this role.

The scene that I focus on here is between Anne and Abigail (played by Emma Stone). Anne is presented as a tetchy and capricious monarch afflicted with physical ailments (she notably had gout) and emotional vulnerabilities that are in part ascribed to her loss of seventeen children in or close to childbirth. She has seventeen pet rabbits, one for each child, and 
the scene shows Abigail manoeuvring her way into the Queen's attention and affection by way of her interest in this peculiar colony, housed in the Queen's bedchamber. ${ }^{1}$ The modal analysis in Table 3.4 is geared to Colman's performance-we could undertake something similar for Stone's performance, but for the sake of concision, we will focus on Colman.

The larger part of Colman's work in this scene, I suggest, is in the emotional modality. She conveys a range that moves from being bored with having rather too much time on her hands, to having her interest pricked by questions concerning the pets-reinforced, we understand, by Abigail's presumed empathy at the loss of her children, which opens into a reading of the character of Anne as defined by sustained and partly repressed grief. The emotional registers here are conveyed in part physically-alterations of eyeline, tilts of the head, flashes of the eye and so forth-along with a rhythm to the performance that evokes its emotional throughline. Colman presents the queen precisely as a regal figure, with a characteristic physicality to do with monarchical sway and inherited position, but also suffused with individual attributes derived from illness, age and circumstance. There is, too, the particular reading of persona in which the actor's deportment meets the imagined corporeality of the character.

Table 3.4 Modal analysis of Olivia Colman's performance in an excerpt from The

Favourite

\begin{tabular}{ll}
\hline The Favourite (2018) \\
\hline Modality & Modes \\
\hline Emotional & Bored \\
& Tetchy \\
& Open \\
& Vulnerable \\
& Grieving \\
& Reactive \\
Physical & Slow \\
& Elegant \\
& Constrained \\
& Explanatory \\
Discursive & Authoritative \\
& Representational \\
Contextual & Relational \\
& Historical \\
& Star vehicle
\end{tabular}


The 'contextual' modality is differently pertinent. The film is based on historical circumstances, so there is inevitably a negotiation in the viewer's mind concerning the balance between an envisaged actuality and the conventions and tactics of dramatization. Colman's appearance as the lead character in an international movie means that we read the performance in relation to conventions and comparators pertaining to Hollywood movies, and not least the trajectory provided by female leads in films dealing with similar monarchical topics: Judi Dench as Queen Victoria in Mrs Brown (1994) and Victoria and Abdul (2017), Cate Blanchett in Elizabeth (1998) or Helen Mirren in the mini-series Elizabeth I (2005), for instance. We may also bring to the movie foreknowledge of previous performances by Colman, Stone and Rachel Weisz (who plays Sarah Churchill), so that the performance mode is coloured by relationality arising from other screen appearances in the lineage of each particular actor.

\subsection{2 ear for eye (2018)}

ear for eye is a play by the British playwright debbie tucker green (who prefers the lower case for her name and the titles of her works). Its inaugural production opened on 31 October 2018 at the Royal Court Theatre in London with tucker green as director. The play is in three parts. The first focuses on exchanges between small groups of characters, specified as African Americans or Black British-for example, a son and his parents, and an activist and an older mentor. The second focuses on a discussion (in part about a mass shooting in the US) between a white male academic and a black female student. The third presents filmed segments in which Caucasian individuals in friendship or family groups recount, verbatim, protocols from the Jim Crow laws affirming racial segregation in the US, and British and French slave codes. The play as a whole, then, presents a series of scenes and sequences in which characters (none of whom we get to know in any close or detailed way) discuss or negotiate nuances of interrelation with others, particularly elaborating on racial perspectives and prejudices and individuals unpack historic and schematic constructions of racial oppression. Here is the beginning of the first scene:

PART ONE

Scene One

US. 


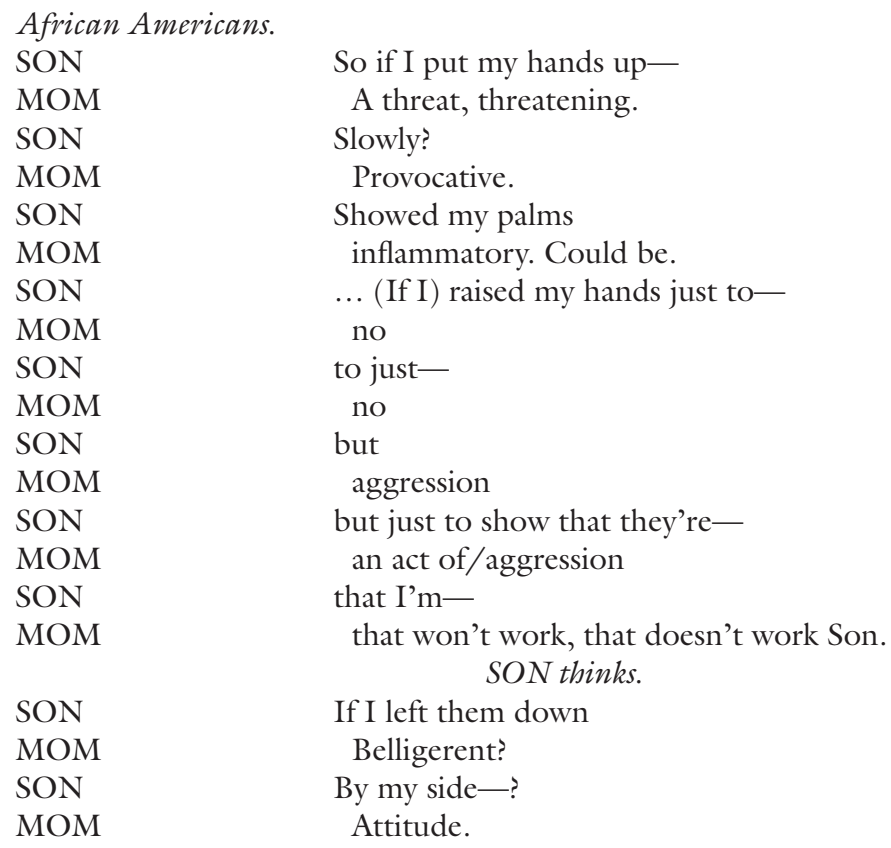

(tucker green 2018: 4; the excerpt from ear for eye by debbie tucker green is reprinted courtesy of Nick Hern Books www.nickhernbooks.co.uk)

Given the stage direction-mother and son are African Americans in the US - we understand the scene in the context of race relations in the US but also more generally. It becomes clear in the scene that from the mother's perspective there is no physical attitude on the part of her son that could not be construed as threatening or provocative by a (presumed white) policeman who chose to interpret his posture in this way. How might we describe the performance envisaged by this text (see Table 3.5 )?

The modes calibrate differently depending on which performer we observe, although the scene as a whole can be characterised in relation to the attributes above. In terms of the emotional modality, the scene depends on our understanding that the mother is concerned for the safety of her son, while he becomes angry at the lengths to which he has to go to avoid her (or an imagined other's) ascription of threat. In the physical modality, both characters are gesturally reactive in response to utterances of their interlocutor, and the physicality of the scene is generally tense and held, 
Table 3.5 Modal analysis of performance in an excerpt from ear for eye

\begin{tabular}{|c|c|}
\hline \multicolumn{2}{|c|}{ ear for eye (2018) } \\
\hline Modality & Modes \\
\hline Emotional & $\begin{array}{l}\text { Focused/task-oriented } \\
\text { Concerned } \\
\text { Angry }\end{array}$ \\
\hline Physical & $\begin{array}{l}\text { Active } \\
\text { Reactive } \\
\text { Constrained } \\
\text { Tense }\end{array}$ \\
\hline Discursive & $\begin{array}{l}\text { Informational } \\
\text { Explanatory } \\
\text { Contextual (triangulated) }\end{array}$ \\
\hline Contextual & $\begin{array}{l}\text { Compositional } \\
\text { Representational } \\
\text { Intertextual }\end{array}$ \\
\hline
\end{tabular}

rather than, say, relaxed and fluid. Discursively, the scene (as with the play as a whole) does not follow key characters in order to tell a story, but rather presents a nugget of exchange that thematises the lived experience of black people amid racism; hence the work of the performers is informational and expressly requires that we read the scene metatextually as an emblem of black experience in the face of oppressive social and civic authority structures. Contextually, the performance provides aesthetic pleasure through the jagged, schematic and non-naturalistic dialogue, thereby asking spectators to recognise it as overtly compositional, while simultaneously it invites recognition of the larger social situation that it depicts, so that the performers' bodies are literally representational-representing (through a set of transparent dramatic devices) the perspective of black citizens - and intertextual in calling to mind the Rodney King beating and other instances of racially motivated police aggression.

The modes and modalities are not entirely self-contained-the intertextual designation, for example, could also belong to the 'discursive' modality. Modes within modalities may vary for individual spectators. For example, the 'contextual' modality might contain aspects of meaning that arise from watching a performance at the Royal Court Theatre, which may be different for a serial visitor interested in 'new writing' (the theatre's programming focus) than for a first-time visitor interested specifically in the topic of the play. Whilst we should be careful to acknowledge that 
reception can vary widely, the modal ensemble allows us to be reasonably precise in categorising the operation of performance in this piece as distinct from other sorts of performance in other situations.

\subsubsection{Black Mirror-'Rachel, Jack and Ashley Too' (2019)}

Black Mirror is a dystopian science fiction series created by Charlie Brooker. Its first two series were broadcast by Channel Four in the UK (the first episode aired on 11 December 2011), before the programme was bought by the video streaming service Netflix. Each episode is selfcontained, typically telling a story with a twist or playing out the envisaged logical conclusions of a future development of contemporary technology - the programme is largely geared around the interface between human agency or insufficiency in relation to the imagined use or exploitation of technology. The episode that I consider here, entitled 'Rachel, Jack and Ashley Too' (directed by Anne Sewitsky), was released as part of Season Five on Netflix and first aired on 5 June 2019. It brings two parallel storylines together. Ashley $\mathrm{O}$, played by Miley Cyrus, is a pop star (like Cyrus in real life). Ashley's management team develops a small robotic toy doll that can interact (largely by talking in a motivational and saccharine way) with its owner. When Ashley starts to rebel against her controlling manager, she is incarcerated. Meanwhile the teenage Rachel (played by Angourie Rice), an Ashley fan, receives one of the dolls as a present. After a device malfunction, the doll speaks not in marketing platitudes but with the 'authentic' voice of the incarcerated star. Various adventures of liberation follow. ${ }^{2}$ In Table 3.6 I suggest some of the predominant modes of Cyrus's performance across the piece as a whole.

'Rachel, Jack and Ashley Too' is inherently multimodal, in the intermedial sense, in that it features pop performance by Ashley alongside scenes showing her being interviewed on television and 'actuality' scenes out of the eye of any diegetic camera. This makes Cyrus's performance as a whole more complex than might be the case in a less modally diverse format. There is - as we might expect - a wide range of modes in the physical modality, covering Ashley's performance as a singer, her appearance as 'pop star' and the more private (and in places comically vulgar) behaviour of the character in a domestic setting. The discursive aspect of Cyrus's performance is not the least complicated part of this piece. Functionally, it reveals plot information; operates across generic registers while indicating a witting manifestation of these registers; presents a character who does not know what is happening to her and who seizes the initiative in a way 
Table 3.6 Modal analysis of Miley Cyrus's performance in Black MirrorRachel, Jack and Ashley Too

\begin{tabular}{ll}
\hline Rachel, Jack and Ashley Too (Black & Mirror, series 5) (2019) \\
\hline Modality & Modes \\
\hline Emotional & Disengaged/unemotional \\
& Focused/task-oriented \\
& Distracted \\
& Happy \\
Angry \\
Active \\
Passive \\
Fhysical & Slow \\
& Composed \\
& Constrained \\
& Uninhibited \\
& Revelatory \\
Knowing \\
Innocent \\
Discursive & Assertive \\
& Presentational \\
& Representational \\
Contextual & Affirmative \\
& Intertextual \\
\end{tabular}

that resonates with feminist and \#MeToo discourse. Contextually, the episode gains traction precisely for the casting of a music star in role as a music star within a dark narrative of exploitation. Meanwhile Cyrus performs a set of modal negotiations (of pop iconicity, trauma, liberation narrative and postmodern intertext) within a single drama-a black mirror indeed.

\subsubsection{Sanctuary (2017)}

Conceived and directed by South African artist Brett Bailey and presented by Third World Bunfight, Sanctuary was first presented at the Fast Forward Festival in Athens on 3 May 2017. ${ }^{3}$ I visited the installation on 9 June 2017 at the Theater der Welt Festival in Hamburg, Germany, and write about it in Lavender (2019: 57-59). Sanctuary is an installation for spectators to walk through. It creates the figure of a maze-the myth of the minotaur is invoked - as the holding pattern for a series of 'stations', 
Table 3.7 Modal analysis of performance in Sanctuary

\begin{tabular}{|c|c|}
\hline \multicolumn{2}{|c|}{ Sanctuary (2017) } \\
\hline Modality & Modes \\
\hline \multirow[t]{3}{*}{ Emotional } & Disengaged/unemotional \\
\hline & Task-oriented \\
\hline & Disinterested \\
\hline \multirow[t]{4}{*}{ Physical } & Passive \\
\hline & Slow \\
\hline & Laboured \\
\hline & Relaxed \\
\hline \multirow[t]{5}{*}{ Discursive } & Revelatory \\
\hline & Knowing \\
\hline & Naïve \\
\hline & Contextual (triangulated) \\
\hline & Innocent \\
\hline \multirow[t]{5}{*}{ Contextual } & Scenographic \\
\hline & Compositional \\
\hline & Presentational \\
\hline & Environmental \\
\hline & Relational \\
\hline
\end{tabular}

each of which features a performer playing a fictional character presented as if actual. The performers do not speak and barely perform any physical action, instead simply sitting or standing in situ, so the human figures here are not so much characterised as displayed. Accompanying segments of text give us to understand that, for example, one character is 'Mahmoud, 36 , dress shop owner' and another is a 23-year-old make-up artist. All are connected by the theme of migration and immigration, and they variously inhabit their stations amid scenographic devices (fences, police tape, orange life jackets) that evoke the holding pens and arrival centres of the contemporary refugee situation. How might we categorise the work of performance in this piece (see Table 3.7)?

The performance of the human figures is modally limited, strikingly so, particularly in the emotional and physical modalities. That is not to say that it is less important to the effect of Sanctuary than the performance in our previous instances. It attains its potency through the discursive and contextual modalities, as we read into it a set of circumstances and histories that are geographically specific while also responding to the larger civic and political crisis of migration (amid systemic failure on the part of nation states to find an adequate set of responses). You might argue that some of the modes that I have included in (for instance) the contextual 
modality-such as scenographic, compositional, presentational - are openended and would apply to any kind of performance. I do not necessarily disagree, but the point is that these modes come to the fore, and the performance thereby attains its distinctness through the specific use of the figure as a symbolic scenographic presence rather than, as with two of my previous examples, a (so to say) fleshed out character. The environmental and relational aspects of the piece partly concern its figurings of actuality and fiction, both thematically (it draws on actual instances of migration, even if it alters these within the fictional scenarios of the event) and by way of the audience's encounter, navigating an actual space which is also designed as a fictive labyrinth. In many ways, Sanctuary is a good example of what Mark Crossley describes as work that is "both distinctly fictional and real" and as "hypermediated theatrical signification" (Crossley 2020: 104).

Sanctuary does not feature character-based or narrative-driven performance, so it is useful here in helping to delineate the scope of a modal approach. In her contribution to the present publication, Kate Newell considers how adaptations of Margaret Atwood's The Handmaid's Taleand in particular accompanying graphic representations such as cover art and illustrations-shape particular responses to the material. As she suggests, "each adaptation foregrounds certain modalities to lead perceivers toward particular interpretations of the communication transfer" (2020: 36). Whilst I have transposed modalities from those outlined by Elleström, a similar principle applies, in that the foregrounding of specific modes within the modalities of performance leads spectators towards particular interpretations. The issue is not that any particular mode is unique or requires definition in an entirely bespoke way in relation to the performance in view. Rather, it is that the modal ensemble defines the performance, and a modal analysis provides insights as to how this ensemble is prepared and presented.

\subsection{Towards a Multimodal Performance Analysis}

Elleström suggests that

Every medium consists of a fusion of modes that are partly, and in different degrees of palpability, shared by other media. [...] Since the world, or rather our perception and conception of the world, is utterly multimodal, all media are more or less multimodal on the level of at least some of the four modalities. (2010: 24) 
If we transpose this to a consideration of modes and modalities of performing, the shared principle is that in performance acts we also observe a fusion of modes, to different degrees, where performance is multimodal with respect to interrelating modes across the four modalities (emotional, physical, discursive and contextual). A focus on modes and modalities allows us to set aside questions about the psychology of characters or the interior drives of actors, in favour of a more interrelational exploration of actions, interactions and conveyances of communicative information. It provides a way of calibrating - either in advance (for training, rehearsal, preparation) or after the event (by way of analysis and critical review) - the constitutive features of any particular performance act.

I have presented here a speculative set of starting points, both as a form of analysis and as a potential set of coordinates for performance preparation. A next step would be to test this in workshop and rehearsal situations, with actors and performers preparing work for public presentation. Might performance be helped, or changed, if the performer pays attention to the respective modalities? Might it take on different nuances if the performer explores the relevant fusion of modes and how the multimodal dynamic shifts as the performance moves along? This is for fresh exploration. We can pause meanwhile at the observation of Bateman et al. that "Modes presented together then need to be interpreted with respect to one another and so cannot be considered independently" (2017: 17). A multimodal approach to performance requires this critical disposition, for the performers in front of us present a complex set of communicative possibilities. They are a channel for intracommunicational elements within the world of the drama or performance event; they operate in relation to extracommunicational features derived from our knowledge of the world; and they are phenomenal figures in their own right, summoning and shaping a communicative repertoire that is inherently multimodal.

\section{Notes}

1. The scene can be viewed at https://www.youtube.com/ watch?v=pG22rNMENSg (accessed 2 September 2019).

2. A trailer for the episode can be viewed at https://www.youtube.com/ watch?v=OY-uKFw4dZM (accessed 2 September 2019).

3. For details, see https://www.onassis.org/whats-on/fast-forward-festival-4/fff4-sanctuary. A trailer for the piece is at https://vimeo. com/249815610 (both accessed 2 September 2019). 


\section{REFERENCES}

Auslander, Philip. 1997. From Acting to Performance. London and New York: Routledge.

Bateman, John, Janina Wildfeuer, and Tuomo Hiippala. 2017. Multimodality: Foundations, Research and Analysis - A Problem-Oriented Introduction. Berlin: Walter de Gruyter.

Benedetti, Jean. 1999 [1988]. Stanislavski: His Life and Art. London: Methuen. Bruhn, Jørgen. 2020. Towards an Intermedial Ecocriticism. In Beyond Media Borders: Intermedial Relations among Multimodal Media, Volume 2, ed. Lars Elleström, 117-148. Basingstoke: Palgrave Macmillan.

Carnicke, Sharon Marie. 2009. Stanislavsky in Focus: An Acting Master for the Twenty-First Century. London and New York: Routledge.

Crossley, Mark. 2020. A Recalibration of Theatre's Hypermediality. In Beyond Media Borders: Intermedial Relations among Multimodal Media, Volume 1, ed. Lars Elleström, 95-112. Basingstoke: Palgrave Macmillan.

Djonov, Emilia, and Sumin Zhao. 2014. From Multimodal to Critical Multimodal Studies Through Popular Discourse. In Critical Multimodal Studies of Popular Discourse, ed. Emilia Djonov and Sumin Zhao, 1-14. New York and London: Routledge.

Dunbar, Zachary, and Stephe Harrop. 2018. Greek Tragedy and the Contemporary Actor. Basingstoke: Palgrave Macmillan.

Elleström, Lars. 2010. The Modalities of Media: A Model for Understanding Intermedial Relations. In Media Borders, Multimodality and Intermediality, ed. Lars Elleström, 11-48. Basingstoke: Palgrave Macmillan.

- 2020. The Modalities of Media II: An Expanded Model for Understanding Intermedial Relations. In Beyond Media Borders: Intermedial Relations among Multimodal Media, Volume 1, ed. Lars Elleström, 3-91. Basingstoke: Palgrave Macmillan.

Espeland, Todd. 2015. The Eight Efforts: Laban Movement. Theatrefolk. https:// www.theatrefolk.com/blog/the-eight-efforts-laban-movement/. Accessed 3 January 2020.

Fernandes, Carla, ed. 2016. Multimodality and Performance. Newcastle upon Tyne: Cambridge Scholars Publishing.

Jackson, Shannon. 2004. Professing Performance: Theatre in the Academy from Philology to Performativity. Cambridge: Cambridge University Press.

Jewitt, Carey. 2014 [2009]. An Introduction to Multimodality. In The Routledge Handbook of Multimodal Analysis, ed. Carey Jewitt, 15-30. London and New York: Routledge.

Kirby, Michael. 1972. On Acting and Not-Acting. The Drama Review 16: 3-15.

Kress, Gunther. 2014 [2009]. What Is Mode? In The Routledge Handbook of Multimodal Analysis, ed. Carey Jewitt, 60-75. London and New York: Routledge. 
Lavender, Andy. 2019. Twenty-First Century Intermediality. In Intermedial Theatre: Principles and Practice, ed. Mark Crossley, 43-61. London: Red Globe Press.

Lotherington, Heather. 2020. Language in Digital Motion: From ABCs to Intermediality and Why This Matters for Language Learning. In Beyond Media Borders: Intermedial Relations among Multimodal Media, Volume 1, ed. Lars Elleström, 217-238. Basingstoke: Palgrave Macmillan.

McKenzie, Jon. 2001. Perform or Else: From Discipline to Performance. London and New York: Routledge.

Newell, Kate. 2020. Transferring Handmaids: Iconography, Adaptation, and Intermediality. In Beyond Media Borders: Intermedial Relations among Multimodal Media, Volume 2, ed. Lars Elleström, 33-57. Basingstoke: Palgrave Macmillan.

Pitches, Jonathan. 2006. Science and the Stanislavsky Tradition of Acting. London and New York: Routledge.

tucker green, debbie. 2018. ear for eye. London: Nick Hern Books.

Vieira, Miriam. 2020. Building Bridges: The Modes of Architecture. In Beyond Media Borders: Intermedial Relations among Multimodal Media, Volume 2, ed. Lars Elleström, 59-77. Basingstoke: Palgrave Macmillan.

Wangh, Stephen. 2000. An Acrobat of the Heart: A Physical Approach to Acting Inspired by the Work of Jerzy Grotowski. New York: Vintage Books.

Open Access This chapter is licensed under the terms of the Creative Commons Attribution 4.0 International License (http://creativecommons.org/licenses/ by $/ 4.0 /$ ), which permits use, sharing, adaptation, distribution and reproduction in any medium or format, as long as you give appropriate credit to the original author(s) and the source, provide a link to the Creative Commons licence and indicate if changes were made.

The images or other third party material in this chapter are included in the chapter's Creative Commons licence, unless indicated otherwise in a credit line to the material. If material is not included in the chapter's Creative Commons licence and your intended use is not permitted by statutory regulation or exceeds the permitted use, you will need to obtain permission directly from the copyright holder.

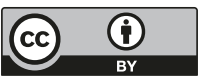

